\title{
Crisis, post-crisis y Estado de Bienestar: ¿hacia dónde transita el Modelo Social Europeo?*
}

\author{
Crisis, Post-Crisis and the Welfare State: \\ Where is the European Social Model Headed to? \\ Rafael Muñoz de Bustillo Llorente \\ Catedrático de Economía Aplicada en Universidad de Salamanca
}

doi: 10.18543/ced-54-2016pp121-154

\begin{abstract}
Sumario: I. Introducción.-II. Los Modelos de Bienestar Europeos en el contexto del Modelo Social Europeo.-III. Resiliencia y cambio del Estado de Bienestar.-IV. Reformas estructurales y cambio en los EB de europeos. 4.1. Reforma sin complejos en el Reino Unido: hacia una sociedad de mercado. 4.2. La integración de política de empleo y asistencia social. El caso Alemán. 4.3. «Here, there and everywhere»: la reforma generalizada de los sistemas de pensiones. 4.4. La reforma global. El caso de los países sujetos a intervención financiera como resultado de la crisis económica de 2008.- - V. Conclusiones.
\end{abstract}

Resumen: La crisis económica, su gestión y la post-crisis han tenido un efecto innegable sobre el desarrollo de los Estados de Bienestar en Europa. Las reformas estructurales desarrolladas han afectado gravemente la fortaleza del Estado de Bienestar ya sea por dirigirse directamente contra él, ya sea por los daños colaterales de la política de ajuste fiscal desarrollada. Este artículo tiene como objetivo valorar hasta qué punto la crisis económica y su gestión, impulsada y avalada por el ECOFIN (Consejo de Asuntos Económicos y Financieros de la Unión Europea), ha afectado a unos Estados de Bienestar europeos que hasta la crisis se habían mostrado, en las grandes líneas de sus actuaciones, razonablemente resilientes a los ataques de los que habían sido objeto durante décadas.

Palabras clave: Estado de Bienestar, Modelo Social Europeo, Crisis.

Abstract: The economic crisis and the economic policy followed to readdress the main economic disequilibrium generated have affected the development of European Welfare States. The structural reforms carried out by most EU States have had a deep impact on the strength of the Welfare States, either because they were directly aim at it, or due to the collateral damage inflicted by the policy of fiscal consolidation followed. This paper aims at reviewing to what extend the economic crisis and its management, driven and backed by the ECFIN (Economic and Financial Affairs Council) has affected European Welfare States, an institution that be-

* Recibido el 23 de septiembre de 2015, aceptado el 27 de enero de 2016. 
fore the crisis has shown a great deal of resilience to confront the attacks aim at it for decades.

Keywords: Welfare State, European Social Model, Crisis.

\section{Introducción ${ }^{1}$}

Hace ya siete años desde que comenzó la crisis económica y financiera internacional, y cinco desde que la Unión Europea cambió sus directrices de política económica pasando de un keynesianismo desganado a una actuación decidida y obsesiva contra el déficit y la deuda pública con la fe del converso. Este cambio de orientación de política económica, que puso a los países con mayores problemas a los pies de los caballos de los «mercados» financieros internacionales, no estaba justificado en su momento, como no lo está en la actualidad. No es este el lugar para tratar la debilidad teórica de la hipótesis de austeridad fiscal ${ }^{2}$, tan ardientemente defendida por las instituciones europeas como débil desde un punto de vista teórico y empírico. Aunque algunos gobiernos, e incluso la propia Comisión Europea, se resistan a reconocerlo, la experiencia de los últimos años ha puesto de manifiesto sin lugar a dudas que la austeridad fiscal, en un momento de recesión y caída de la demanda interna generalizada, genera más recesión, prolongando la crisis. La segunda recesión de 2011 es un claro ejemplo de ello. Cuando las economías europeas, y la española entre ellas, parecía recuperarse como resultado de la acción contracíclica presupuestaria aplicada, el cambio de política económica y la prioridad otorgada a la lucha contra el déficit truncó la recuperación situando a la UE (Unión Europea), y a España, de nuevo, en tasas de crecimiento negativas. En este sentido, no deja de ser elocuente que la recuperación experimentada en 2014 por la economía española se haya producido justo cuando se han relajado los objetivos de reducción de déficit, retrasando los plazos hasta alcanzar el mítico $3 \%$.

${ }^{1}$ El autor agradece a Rafael Bonete las sugerencias realizadas a una versión previa de este trabajo.

2 Sobre esta cuestión véase, por ejemplo, MUÑOZ DE BUSTILLO, R., «Questioning the myth of expansionary austerity: European macroeconomic policy during the crisis and its aftermath», en BILBAO UBILLOS, J. (ed.), The Economic Crisis and Governance in the European Union. A critical assessment, Routledge, Oxon 2014, pp: 114-133, y MUÑOZ DE BUSTILLO, R., «La construcción de un mito: la Hipótesis de Austeridad Expansiva», en GUERRA, A. y TEZANOS, J. F. (eds.), Los retos de Europa: democracia y bienestar social, Editorial Sistema, Madrid 2012, pp. 115-147. 


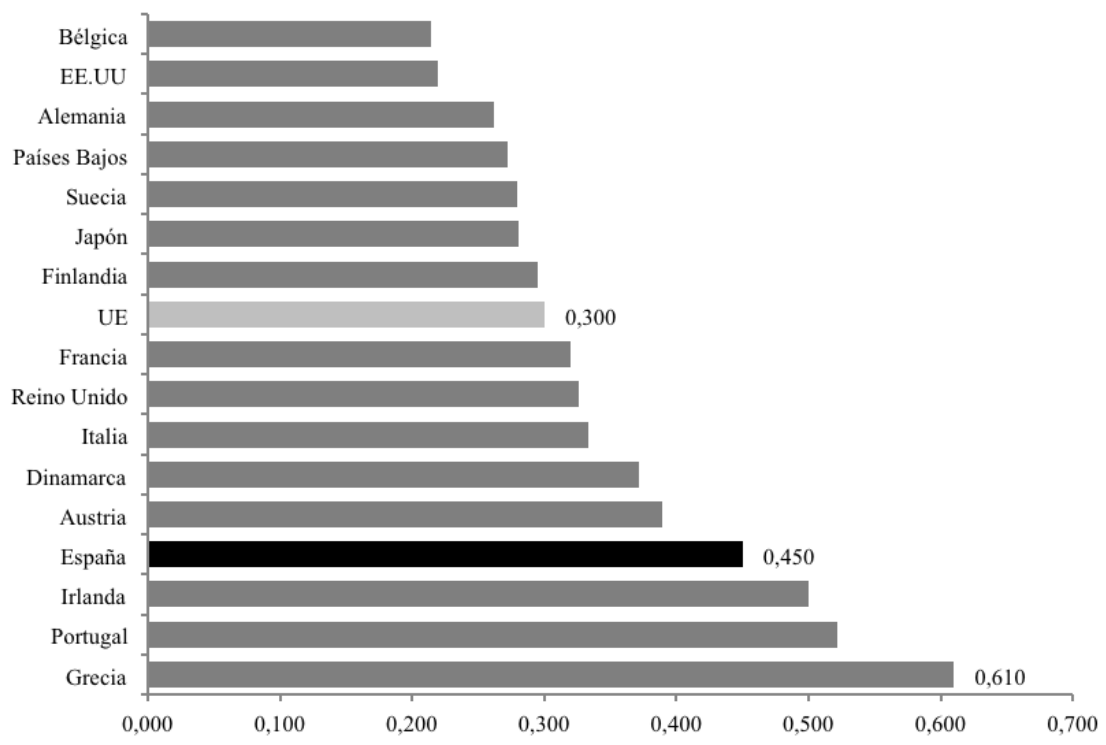

Figura 1

Índice de reformas estructurales para el crecimiento de la OCDE, 2007-2014

Fuente: adaptado de OECD Going for Growth 2015. OECD, Paris 2015, p. 109

La futilidad, y el daño ocasionado por la política de lucha contra el déficit y las correspondientes «reformas estructurales» en un contexto recesivo, se observa de forma clara en el Gráfico 1. Este gráfico recoge la evaluación realizada por la OCDE (Organización para la Cooperación y el Desarrollo Económico) del cumplimiento de los objetivos de reforma estructural en ámbitos relacionados con el mercado de trabajo (costes laborales, incentivos al trabajo, incentivos para la incorporación al mercado de trabajo, regulación laboral) y la productividad (ámbito de la intervención pública, barreras a la creación de empresas, barreras al comercio y a la inversión extranjera directa, apoyo a la innovación e imposición), agregándolos en un indicador que permite la comparación entre países en una especia de «liga reformadora». Para facilitar la lectura, el gráfico solo reproduce los indicadores correspondientes a los países de la UE (15) junto con Japón y Estados Unidos. El resultado no puede ser más elocuente. Los países que según la OCDE han seguido con mayor fidelidad e intensidad las recomendaciones de la OCDE, curiosamente los países intervenidos (de forma o de facto, como España), no parecen haber cosechado los 
réditos prometidos. En palabras de $\mathrm{Keen}^{3}$, y por mucho que se defienda lo contrario desde las instituciones oficiales y oficiosas: «Los reformadores en las primeras posiciones son los casos perdidos de Europa. El desempleo en Grecia es el 27\%, en Portugal el 15\%, en Irlanda el 12\%, y en España el $25 \%$. Son economías muy enfermas. Y, sin embargo son los líderes reformistas según la OCDE».

Podríamos dar muchos más ejemplos, tan elocuentes como el anterior, que ponen de manifiesto el fracaso de la estrategia seguida y los innecesarios sacrificios derivados de ella. Pero ese no es el objetivo de estas páginas. Como indica el título del artículo, la crisis económica, su gestión y la post-crisis han tenido un efecto innegable sobre el desarrollo de los Estados de Bienestar, EB, en Europa. Las reformas estructurales encapsuladas en el indicador reproducido en el gráfico anterior han afectado gravemente la fortaleza del EB ya sea por dirigirse directamente contra él, ya sea por los daños colaterales de la política de ajuste fiscal. Este artículo tiene como objetivo valorar hasta qué punto la crisis económica, y su gestión impulsada y avalada por la formación más poderosa del Consejo de la UE (el ECFIN), ha afectado a unos Estados de Bienestar europeos que hasta la crisis se habían mostrado en las grandes líneas de sus actuaciones razonablemente resilientes a los ataques de los que habían sido objeto durante décadas. Paradójicamente, una crisis provocada por la aplicación de las políticas más liberales en los ámbitos de la desregulación financiera habría acabado poniendo en peligro precisamente a las instituciones que tuvieron que acudir a su rescate.

Con esa finalidad, en las sección 2 debatiremos hasta qué punto se puede hablar de Modelo Social Europeo, tanto por la diversidad de las políticas sociales existentes en su seno como por la bipolaridad de la que han hecho gala las instituciones de gobierno de la UE en lo que respecta a esta materia. En la sección 3, se realizará un breve recorrido por las grandes líneas de comportamiento de los EB (Estado de Bienstar) europeos antes de la crisis, centrándonos en binomio de continuidad y cambio. La sección 4, estudiará de qué forma las políticas aplicadas en los últimos años, especialmente las denominadas reformas estructurales, han afectado a los EB europeos, centrándonos en algunos países y políticas específicas como las pensiones, la reforma de las prestaciones por desempleo y el mercado de trabajo o los ajustes estructurales vinculados a los programas de intervención financiera. Por último, en la sección 5, a modo de conclusiones, se valorará cuáles puedes ser las consecuencias futuras de los cambios acontecidos.

${ }^{3}$ KEEN, S., «For Greece and Many Others, Economic Reform Is Bad For Your Economic Health» en Forbes, 17 febrero 2015. 


\section{Los Modelos de Bienestar Europeos en el contexto del Modelo Social Europeo}

Basta con observar el distinto peso que los «gastos sociales extendidos» (esto es, incluyendo educación $)^{4}$ tienen sobre el PIB de los países de la UE (Gráfico 2) para comprobar la enorme diferencia existente en el esfuerzo que los distintos países realizan en materia de protección social. Más aún, esa diferencia ni parece haberse reducido de forma radical en el pasado, ni es sólo el resultado de las distintas circunstancias objetivas a las que se enfrentan los países miembros.

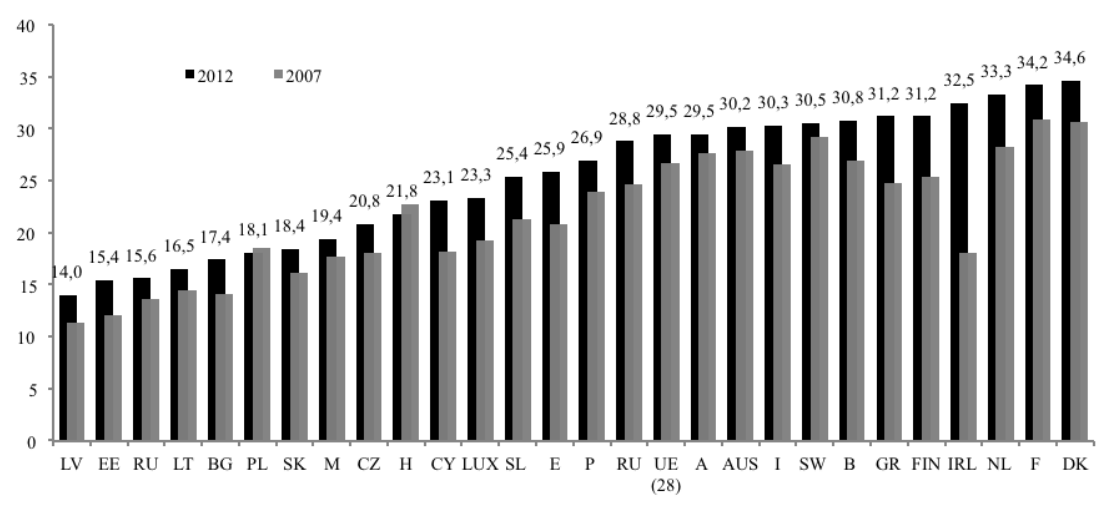

\section{Gráfico 2}

Gasto social/ PIB (\%) antes y durante la crisis (2007 y 2012)

Fuente: Eurostat y elaboración propia

${ }^{4}$ Aunque en los años ochenta del pasado siglo era habitual considerar los gastos en educación como gastos sociales, con el paso del tiempo, y en parte asociado a la adopción de la metodología ESSPROS Eurostat's European System of Social Protection Statistics por parte de la UE, los gastos en educación han pasado a excluirse de los gastos sociales. De este modo, de acuerdo con la metodología de la OCDE, The Social Expenditure database: An Interpretive Guide SOCX 1980-2003, Paris 2007, se consideran gastos sociales: «La provisión por parte de instituciones públicas y privadas (...) de prestaciones de apoyo durante circunstancias que afectan negativamente a su bienestar» (p.6), lo que excluye claramente los gastos en educación (salvo los vinculados con las guarderías o pre-escolares). Cosa distinta es que al referirnos al EB haya que adoptar la misma perspectiva. Desde esta perspectiva más amplia, la educación debería considerarse elemento consustancial del EB por su fuerte efecto sobre la movilidad social y su papel como herramienta de igualdad de oportunidades. A menudo, sin embargo, a la hora de cuantificar el EB se tiende a hacer uso de las estadísticas más directamente disponibles de gasto social, lo que en la práctica supone dejar a un lado el gasto en educación. 
En lo que a la primera cuestión se refiere, la existencia de convergencia en materia de esfuerzo social, la desviación estándar, esa vieja y buena medida de desigualdad que - en contraste con otras comúnmente usadas - responde a las diferencias absolutas y no sólo a las relativas ${ }^{5}$, nos permite aproximarnos de forma sencilla al tema. En el Cuadro 2 se reproduce el comportamiento de la desviación estándar del esfuerzo relativo en protección social, desde 1990, de los países de la UE (15) y para el conjunto de la UE, (en este caso de geometría variable ya que el número de países va aumentando según nos aproximamos al final de periodo contemplado en la serie con las sucesivas ampliaciones de la UE). Como se puede apreciar, la dinámica es distinta según se toma una u otra muestra de países. Para la UE (15) se observa cierta convergencia hasta la crisis, con una reducción significativa de la desviación estándar en un tercio de su valor entre 1995 y 2007. Esta reducción se aceleraría con la crisis, cayendo seis puntos porcentuales más de 2008 a 2012. Esta convergencia, sin embargo, esconde dos dinámicas de muy distinta naturaleza.

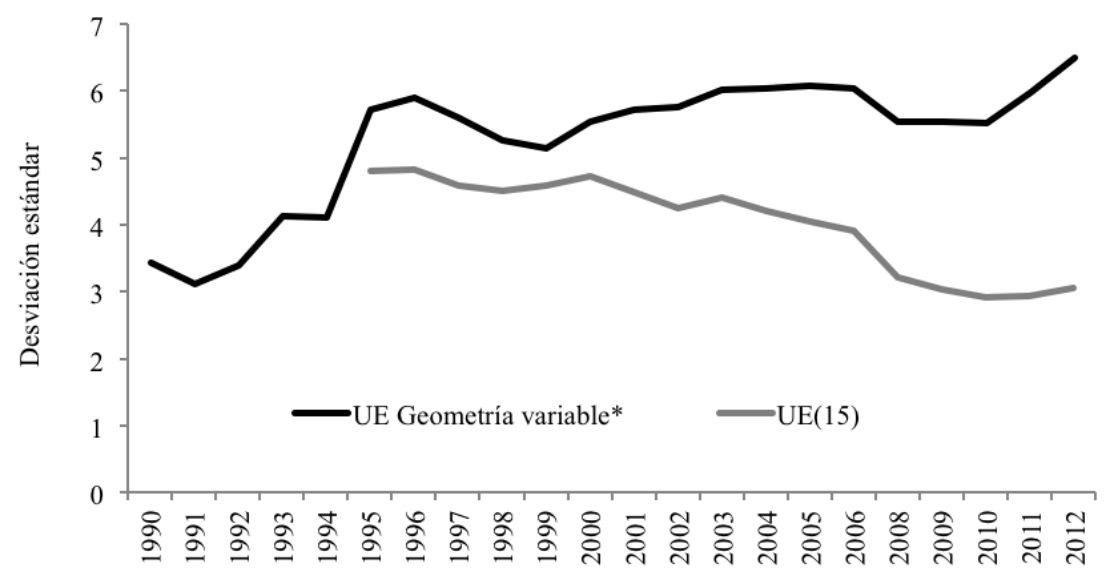

\section{Gráfico 2}

Desviación estándar del esfuerzo en protección social en la UE.

Fuente: Eurostat y elaboración propia.

5 KOLM, S. C., «Unequal Inequalities II» en Journal of Economic Theory, n. . 13, 1976, pp. 82-111. 
En el primero de los periodos observados la reducción en las disparidades de esfuerzo en protección social dentro de la UE (15) se produce por una caída del esfuerzo en protección social de los países con un mayor desarrollo del EB, y no por crecimiento del gasto social en los países más retrasados en este campo. Con la crisis, sin embargo, se produce un aumento del esfuerzo en gasto social (en parte, pero no solo, como efecto estadístico debido a la caída del PIB) en todos los países - con las excepciones de Hungría y Polonia - en términos globales más intensos en los países con menor desarrollo del EB.

En lo que al segundo elemento se refiere, los análisis econométricos nos indican que las variables «objetivas» determinantes del gasto social no son capaces de explicar por si solas las profundas diferencias existentes entre los países europeos en materia de esfuerzo en protección social. Así, si ajustamos una función lineal tomando como variable independiente el esfuerzo en protección social como porcentaje del PIB y como variables independientes: (a) nivel de desarrollo del país medido según su PIB per cápita en PPA (Paridad de Poder Adquisitivo), (b) población menor de 15 años (que afectaría a los gastos en ayuda familiar), (c) población mayor de 65 (que afectaría a los gastos en pensiones y en menor medida a los gastos en salud) y (d) tasa de desempleo (que afectaría a los gastos en política de empleo), el resultado obtenido, con un $\mathrm{R}^{2}$ del $48 \%$ en 2007 y $52 \%$ en 2012 , nos indicaría que las diferencias en estas variables objetivas sólo explicarían alrededor de la mitad de las diferencias en esfuerzo social, estando el resto explicado por las distintas opciones tomadas a la hora de priorizar las políticas sociales frente a otros objetivos. Los resultados, cuando se toma el esfuerzo social extendido (gasto social más educación) son similares. De esta forma, podemos decir que, en una parte nada desdeñable las diferencias detectadas en materia de esfuerzo en protección social en la UE responden a opciones distintas de política económica, al respaldo de distintas concepciones de lo que es una «buena sociedad».

La existencia de distintos modelos de EB en el seno de la UE es algo que se ha estudiado con detalle en el pasado, dando lugar a toda una línea de investigación dirigida a identificar las características de los mismos y su adscripción a «familias» o tipos idiosincráticos de Estados de Bienestar. Este debate, en gran parte taxonómico, tiene un importante hito en la propuesta analítica de Esping-Andersen ${ }^{6}$, que distingue tres modelos de EB: socialdemócrata, corporatista y liberal, a partir del análisis de tres políticas de gasto: pensiones de vejez, pensiones de enfermedad y desempleo. Con el paso del tiempo, esta literatura ha ido incorporando nuevas familias o mo-

${ }^{6}$ ESPING-ANDERSEN, G., The Three Worlds of Welfare Capitalism, Polity, Oxford 1990. 
delos de EB, bien como resultado de críticas a la posición que ocupaban países concretos en la trilogía de Esping-Andersen, bien como resultado de la incorporación de nuevos países no contemplados en ésta. Ello ocurriría primero con los Países Mediterráneos, y con posterioridad con los Países del Este y del Centro de Europa tras la caída del Muro de Berlín. Las limitaciones de extensión del artículo nos impiden detenernos en la revisión de esta literatura ${ }^{7}$, en todo caso es imprescindible resaltar las implicaciones del importante trabajo realizado por Allen y Scruggs ${ }^{8}$, quienes tras replicar y redefinir la metodología de Esping-Andersen concluyen que los EB están muy lejos de conformar modelos puros, proponiendo una visión diferente según la cual sería más apropiado hablar en términos de modelos de programas de bienestar que de modelos de EB, en el sentido de que los EB no necesariamente guardarían coherencia interna en lo que se refiere al diseño de los distintos programas de política social. La realidad, como en tantas otras áreas, sería más caótica, menos predecible de lo que apuntaría la idea de existencia de «modelos» de bienestar.

Esta diversidad no contingente, en la medida en que como hemos visto más arriba no desaparece con el paso del tiempo, no sólo tiene implicaciones a la hora de dotar de contenido al Modelo Social Europeo, sino que puede ser el origen de tensiones desestabilizadoras de la UE y de los propios EB europeos. Nos referimos al debate sobre la compatibilidad de un mercado común de bienes, servicios, personas y capitales - un único mercado interno - en un contexto de fragmentación de las políticas sociales, donde el peso de la protección social recae sobre los estados nacionales.

En todo caso, a los conocedores del proceso de construcción europea no debería sorprenderles la diversidad de los EB europeos. La UE nunca tuvo entre sus objetivos la «comunitarización» de la política social. Cierto es que en los debates conducentes al Tratado de Roma, el primer ministro francés, Guy Mollet defendió la armonización fiscal y social como requisito para la integración, pero al final triunfaron otros intereses y visiones de la integración, dejando la armonización social en manos de la convergencia económica y social que se esperaba se produciría de forma natural con la integración comercial y por las políticas nacionales ${ }^{9}$.

${ }^{7}$ Una revisión de esta literatura se puede encontrar en ARTS, W. Y GELISSEN J., «Three worlds of welfare capitalism or more? A state-of-the-art report» en Journal of European Social Policy 12, n. ${ }^{\circ}$ 2, 2002, pp. 137-158.

8 SCRUGGS, L. y ALLAN, J., «Welfare State Decommodification in 18 OECD Countries: A Replication and Revision» en Journal of European Social Policy, 16, n. ${ }^{\circ} 1,2006$, pp. 55-72.

9 SCHARPF, F. W., The European Social Model: Coping with the Challenges of Diversity, MPIfG Working Paper 02/8, July, Cologne, Max-Planck-Institute for the Study of Societies 2002 . 
Más aún, se podría decir que la política social sobresale en los tratados por las referencias a la soberanía de los EEMM (Estados Miembros) en lo que se refiere a las actuaciones en su ámbito, y no por las intervenciones proactivas de las instituciones comunitarias en esta materia ${ }^{10}$. Y cuando así lo hace se recurre cada vez con más frecuencia a mecanismos legislativos «blandos» como el Método Abierto de Coordinación, MAC, en vez de a los tradicionales mecanismos «duros» de Directivas y su obligatoria trasposición por los EEMM a la legislación nacional. Aunque se puede argumen$\operatorname{tar}^{11}$ que la ley dura no siempre lo es tanto como formalmente pudiera parecer, ni el MAC tan blando como se piensa, el hecho es que las actuaciones en el marco de la política social, comparado con otros ámbitos de intervención comunitaria, han sido tímidas y frecuentemente voluntaristas en vez de ambiciosas y obligatorias.

Sin minusvalorar ni las actuaciones puntuales ni las grandes declaraciones de respaldo al EB que de tanto en tanto se realizan desde distintas instituciones comunitarias, el repaso de la actividad comunitaria en este ámbito deja en evidencia la asimetría existente entre las actuaciones comunitarias en la materia (tiempo de trabajo, seguridad e higiene en el trabajo o igualdad de oportunidades, etc.) y las intervenciones nacionales en este ámbito centradas en la protección frente al riesgo mediante grandes programas de pensiones, salud, prestaciones por desempleo y protección familiar y lucha contra la pobreza, con unas exigencias presupuestarias incomparablemente mayores y fuertes implicaciones en términos de redistribución de la renta. En definitiva, dos mundos distintos.

Casi podríamos decir, en lo que a esto respecta, que hay que esperar a la Gran Crisis y a la intervención financiera de países como Irlanda, Portugal, Grecia, Chipre y España (en este último caso una intervención formalmente limitada al sector financiero) para escuchar desde la UE pronunciamientos vinculantes en materia de Política Social con mayúscula, si bien en este caso por mecanismos al margen de los tratados y dirigidos a la reducción del gasto social y el redimensionamiento a la baja del EB y no a su consolidación y fortalecimiento.

En lo que a esto respecta es importante señalar, ya para terminar esta sección, la existencia de dos mensajes contrapuesto en lo que se refiere a la política social y el EB en la UE, dos mensajes que se pueden interpretar en

${ }^{10}$ Formalmente, el art. 4 del Tratado de Funcionamiento de la UE nos dice que la política social, como el medio ambiente, la agricultura o la política de cohesión, es una competencia compartida entre la Unión y los Estados miembros.

11 TRUBEK, D. M. y TRUBEK, L. G., «Hard and Soft Law in the Construction of Social Europe: the Role of the Open Method of Co-ordination» en European Law Journal, 11, n. ${ }^{\circ} .3$, May 2005, pp 343-364. 
términos de existencia de un conflicto bipolar en las instituciones comunitarias. Por un lado, existen toda una serie de declaraciones a favor de la protección y la cohesión social (con reflejo en los tratados) y del denominado Modelo Social Europeo como elemento consustancial de la UE. Por otro, una visión de la protección social y las actuaciones del EB como palos en la rueda del crecimiento económico y la eficiencia asignativa.

De hecho, como apuntan Hansen y Schierup ${ }^{12}$, la Estrategia de Lisboa se puede interpretar como un intento de solucionar este conflicto, si bien, al hacerlo se plantea una visión de la protección social subordinada a otros objetivos, ya que la misma pasa a ser un elemento más de la ventaja competitiva de la UE. Esto es, las intervenciones sociales tienen valor y fundamentan su razón de ser en la medida en que sirvan para potenciar el crecimiento económico y la competitividad. Esta perspectiva, que en un primer momento se puede considerar que sirve para romper la paradigmática visión economicista de existencia de un trade-off entre eficiencia y distribución, y por lo tanto reforzar el EB, de hecho, corre el peligro de que sirva para facilitar el diseño de un EB dirigido a dicho objetivo, justificando el abandono de aquellos gastos sociales no productivistas. El cambio del discurso de la «decomodificación» y los derechos sociales a las reformas estructurales y la empleabilidad se puede interpretar como reflejo de dicha estrategia.

En definitiva, el conflicto bipolar se resuelve planteando el gasto social como una herramienta más de eficiencia económica. Pero esto supone cerrar el problema en falso, ya que en los casos en los que la protección social sea antagónica de otros objetivos económicos, la adopción de una visión productivista de la misma podría sentar las bases para su abandono, ya que, en definitiva, la protección social no se justificaría per se, por la visión suscrita de lo que es una buena sociedad, sino por su función como instrumento competitivo.

\section{Resiliencia y cambio del Estado de Bienestar}

Tomando como referencia el esfuerzo en protección social, el comportamiento del EB en los países centrales de la Unión Europea durante las últimas dos décadas, tal y como se reproduce en el Gráfico 3, se podría calificar de básicamente estable. A pesar de las frecuentes llamadas

12 HANSEN, P. y SCHIERUP, C., «Still a European Social Model? From a Vision of a 'Social Europe' to the EU Reality of Embedded Neo-liberalism» en Centre for Urban and Ethnics Studies, CEUS, The MES Occasional papers and reprints on Ethnics Studies 26, 2005. 
de atención tanto sobre la crisis del EB y su sostenibilidad económica como sobre su misma deseabilidad, de la observación del gráfico no parecería que, en términos agregados, éste hubiera reducido su peso en el conjunto de la economía. Si acaso con la crisis y tal y como sería de esperar, dado el funcionamiento contracíclico de determinados programas de protección social (prestaciones por desempleo) y el funcionamiento «acíclico» de otros (salud o pensiones), se habría producido un aumento del peso del EB en la economía y no lo contrario. Según esta perspectiva cuantitativa, el EB habría demostrado, al menos hasta la crisis, un alto grado de resiliencia, palabra importada de la ecología que hace referencia a la capacidad de los organismos a adaptarse y sobrevivir al cambio de su entorno. En estos mismos términos se expresaba hace casi veinte años Pierson ${ }^{13}$, uno de los primeros autores en llamar la atención sobre la resistencia del EB ante los brutales ataques políticos de los gobiernos de Margaret Thatcher en el Reino Unido y Ronald Reagan en EE.UU: «Las presiones económicas, políticas y sociales han trasmitido la imagen de un EB acorralado. Sin embargo, cuando se pasa de las discusiones abstractas sobre transformación social al examen de las políticas adoptadas, es difícil mantener la posición de que tales presiones hayan generado cambios fundamentales» (p. 176).

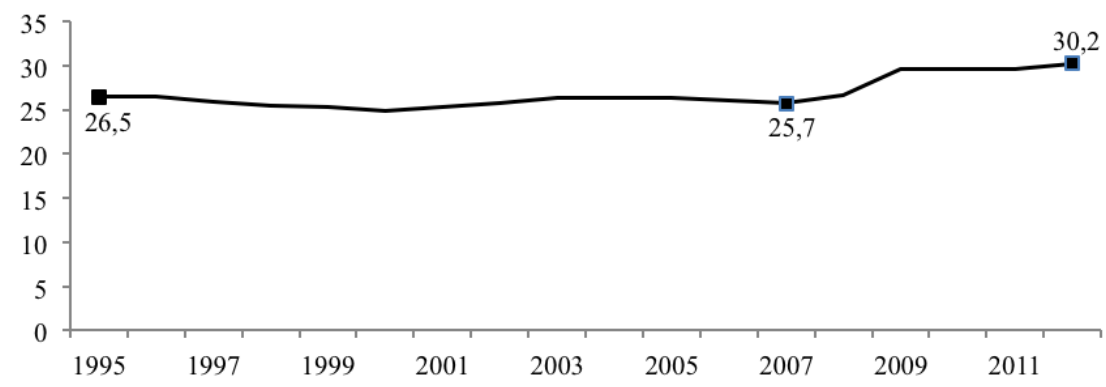

Gráfico 3

Gasto social como \% del PIB. UE(15), 1995-2012

Fuente: Eurostat y elaboración propia.

13 PIERSON, P., «The New politics of the Welfare State», World Politics, vol.48, n. ${ }^{\circ} 2$, 1996, pp 143-179. 
Ahora bien, ¿significa ello que no hay motivo de alarma? ¿Podemos decir, por lo tanto, que el EB sigue business as usual? Para intentar responder esta pregunta acudiremos a una vía distinta de medición del comportamiento del EB, el estudio de la «generosidad» de algunos programas del EB (pensiones de vejez y enfermedad y prestaciones por desempleo) evaluada mediante dos variables: los requisitos necesarios para tener derecho a dichas prestaciones, y el grado de sustitución de rentas de la prestación con respecto a los ingresos laborales previos. En el Gráfico 4 se reproducen, a modo de ejemplo los resultados obtenidos para Alemania, Francia, Reino Unido y Suecia, países que representarían los tradicionales modelos corporatistas, socialdemócrata, y liberal de EB, a partir de las estimaciones realizadas por Scruggs y Allan para el período 1971-2001. Junto con el valor estimado del índice de generosidad, se ha incorporado una función ajustada a dichos valores para reflejar la tendencia temporal del mismo. Del gráfico se desprenden las siguientes conclusiones: (1) Como vimos al hablar del proceso de convergencia, los países con mayor nivel de generosidad: Suecia, Alemania y Francia experimentan un comportamiento creciente de esta variable hasta finales de la década de los 80 , para caer desde entonces. (2) Esta caída supone un cambio de tendencia que reconduce los valores a niveles similares a los existentes una década antes, situándose, en todo caso, al final del periodo en valores superiores a los de partida. En conjunto, por lo tanto, esta vía alternativa tampoco refleja la existencia de una alteración radical de la lógica de las prestaciones ni de su intensidad protectora.

Estas conclusiones, sin embargo, han sido cuestionadas por toda una línea relativamente moderna de análisis centrada en el estudio de las distintas posibles dinámicas de cambio institucional, algunas de ellas no siempre evidentes a primera vista. De acuerdo con esta perspectiva ${ }^{14}$, la existencia de cambios importantes en el EB puede ser compatible con la ausencia de cambios significativos en variables agregadas como el esfuerzo social, o en la normativa que regula el acceso a prestaciones sociales. Esta perspectiva considera que las políticas de cambio radical en las prestaciones sociales o de reducción de su dotación presupuestaria no agotan el abanico de políticas de reestructuración y debilitamiento del EB. Junto a estas medidas abiertas, existirían toda otra serie de políticas ocultas con idénticas implicaciones en términos de supervivencia del EB a largo plazo.

${ }^{14}$ STREECK, W., y THELEN, K. (eds.), Beyond Continuity: Institutional Change in Advanced Political Economies, Oxford University Press, Oxford 2005. HACKER J.S., «Privatizing Risk without Privatizing the Welfare State: The Hidden Politics of Social Policy Retrenchment in the United States» en American Political Science Review, vol. 98, n. ${ }^{\circ}$, , 2004, pp. 243-260. 

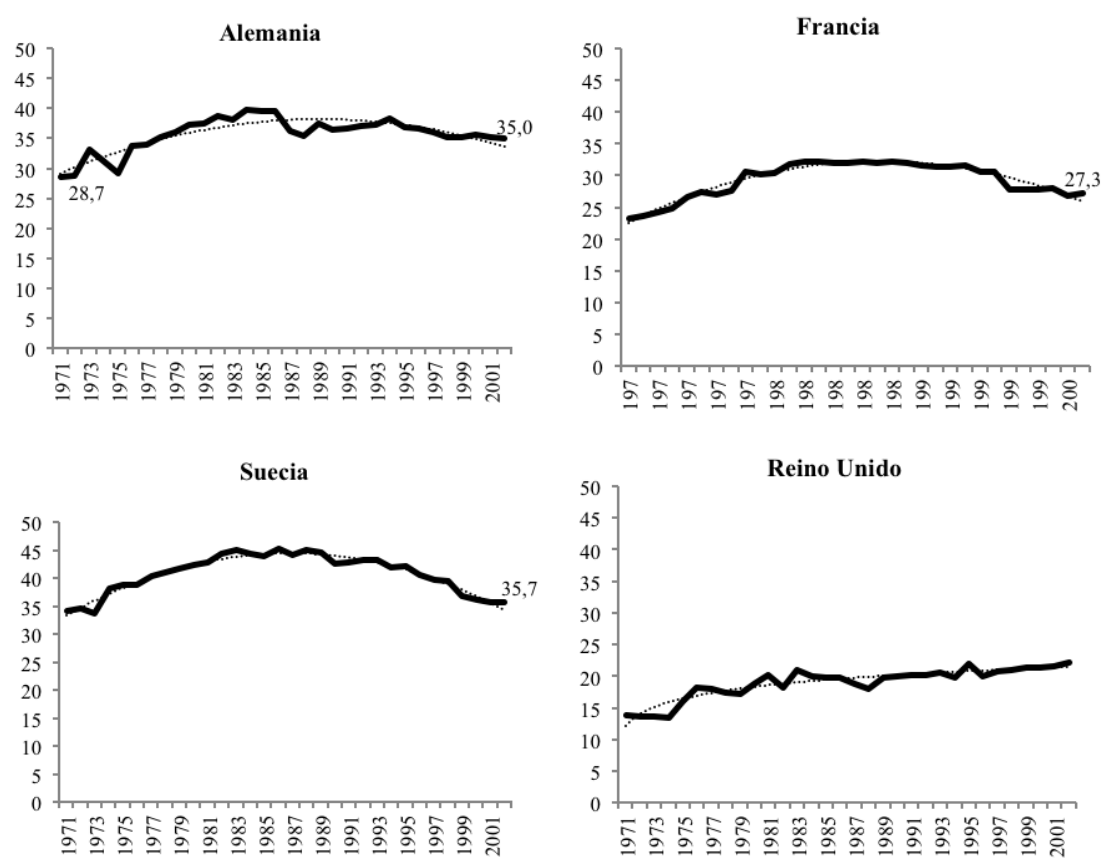

\section{Gráfico 4}

Índice de Generosidad de Scruggs y Allan para varios países desarrollados (19712002)

Fuente: Elaboración propia a partir de Scruggs y Allan op. cit..

La primera de estas vías pasa por la puesta en marcha de una política de debilitamiento basada en la existencia de una brecha entre los presupuestos asignados a determinada política y las necesidades presupuestarias para mantener la calidad de la misma. En un contexto de necesidades crecientes, el mantenimiento de los presupuestos en términos de PIB puede conducir a un empeoramiento de las prestaciones que no aparecería en los indicadores más genéricos de esfuerzo social. Este empeoramiento de las prestaciones puede, a su vez, con el paso del tiempo, generar una pérdida de apoyo al EB por parte de la población y el correspondiente ejercicio de la opción salida por parte de aquellos ciudadanos que puedan ejercitarla al disponer de capacidad financiera suficiente, poniendo en marcha una dinámica de «residualización» de la prestación que haga más fácil su eliminación en el futuro. 
Una segunda vía es la falta de adaptación de las políticas del EB a las necesidades cambiantes de la población. En un contexto de aparición de nuevos riesgos, la no adaptación o ampliación de las políticas de protección social supondrá el abandono del EB de espacios de riesgo con importancia creciente sobre el bienestar y la seguridad de los ciudadanos y ciudadanas. En este caso, sin necesidad de que haya cambios en las políticas vigentes ni en su financiación, se producirá un deterioro de la protección social y del EB, asociado a su renuncia a ejercer como asegurador social ante los nuevos riesgos. Está vía, denominada drift - o deriva - en la literatura, puede ser el resultado de cambios naturales en las características de la población protegida y los riesgos a los que se enfrentan, pero también puede ser el resultado de la negativa consciente a adaptar las políticas sociales a los cambios detectados. En palabras de Hacker: «simplemente mediante el bloqueo de intervenciones compensatorias diseñadas para reducir los riesgos crecientes se puede gradualmente transformar la orientación de los programas» ${ }^{15}$.

El desmantelamiento de políticas sociales con fuerte apoyo ciudadano, como lo son los programas centrales del EB, tiene unos costes políticos que dificultan su eliminación o transformación radical. Ello no significa, sin embargo, que no haya estrategias de debilitamiento que a largo plazo puedan llevar a su desaparición. Una de esas estrategias, la tercera en nuestra relación, es la que, siguiendo a Schickler ${ }^{16}$, se ha denominado layering y que se podría traducir por transformación por capas. Esta estrategia consiste en el debilitamiento de determinada institución mediante la superposición de otra u otras instituciones sustitutivas alternativas. Un ejemplo clásico de este tipo de estrategia es el apoyo a la creación de planes privados de pensiones con la finalidad de minar los planes tradicionales de reparto. Otro ejemplo de esta política lo proporciona la política de subvenciones a escuelas privadas en paralelo a los sistemas educativos públicos, ${ }^{17}$ y que puede conducir a la pérdida del carácter de la educación como institución universal dando lugar a un creciente sistema «particularista» basado en escuelas independientes, con implicaciones en muchos ámbitos, incluyendo el crecimiento del capital social ${ }^{18}$. En lo que a esto

15 Vid. HACKER, J.S., op. cit., nota 14, p. 246.

${ }^{16}$ SCHICKLER, E., Disjointed Pluralism. Institutional Innovation and the Development of the U.S. Congress, Princeton University Press, Princeton, 2001.

17 ROTHSTEIN, B., Just institutions matter: the moral and political logic of the universal welfare state, Cambridge University Press, Cambridge, 1998.

18 ENGLUND, T., «The General School System as a Universal or a Particular Institution and Its Role in the Formation of Social Capital», en Scandinavian Journal of Educational Research, 53, n. ${ }^{\circ} 1,2009$, pp. 17-33. 
respecta, la pregunta crucial, como señalan Streek y Thelen ${ }^{19}$, es hasta qué punto estas instituciones pueden convivir en el tiempo o si la nueva capa institucional acabará vaciando de contenido y usuarios a la original, provocando su desaparición. En la evaluación de los resultados de esta estrategia es también fundamental conocer hasta qué punto la nueva capa que acaba sustituyendo a la antigua institución altera los objetivos o los principios de funcionamiento de la misma, o si tan sólo supone un cambio en la forma de llevarlos a cabo.

Una cuarta vía de cambio oculto es lo que Thelen ${ }^{20}$ denomina conversión, término por el que se hace referencia a la transformación de los objetivos de determinada institución. En este caso la institución no desaparece, pero transforma su función. La utilización de las estructuras de asistencia social en instituciones tendentes a la inserción de los beneficiarios en el mercado de trabajo fruto del paso del welfare al workfare sería un ejemplo de este tipo de cambio.

Por último, y complementaria o independientemente a las anteriores estrategias, es posible que pequeñas transformaciones de la normativa o los presupuestos del EB, con un impacto poco apreciable en el presente acaben, por acumulación, generando cambios significativos en el futuro.

El debilitamiento, la deriva, la transformación por capas, la conversión y el cambio acumulativo, aparecen así como mecanismos ocultos de cambio del EB perfectamente compatibles con la estabilidad del esfuerzo en protección social y los requerimientos y generosidad de las prestaciones. De entre todos ellos, la deriva, esto es, la aparición de una brecha entre las instituciones de bienestar y los nuevos riesgos a los que se enfrentan los ciudadanos, es la estrategia que más atención ha recibido. Pero todas ellas son potencialmente peligrosas para el mantenimiento del EB, al tiempo que relativamente opacas para los análisis agregados.

\section{Reformas estructurales y cambio en los EB europeos}

Las llamadas reformas estructurales tienen su origen en el cambio de paradigma económico acontecido en la década de los 70, con el abandono del keynesianismo y la adopción de una visión de la economía y el funcionamiento de los mercados centrada en el lado de la oferta. Desde esta perspectiva, la clave para el buen funcionamiento de las economías de mer-

19 Vid. STREECK, W. y THELEN, K., op. cit., nota 14.

20 THELEN, K., «How Institutions evolve: Insights from Comparative-Historical Analysis» en MAHONEY, J. y RUESCHEMEYET, D., (eds.), Comparative Historical Analysis in the Social Sciences, Cambridge University Press, New York. 
cado es la eliminación de aquellas restricciones, institucionales o de otro tipo, que puedan impedir el normal (y eficiente) funcionamiento de los mercados. Esta confianza, casi religiosa, en el virtuoso funcionamiento de los mercados en ausencia de intervención externa alcanza el paroxismo en la hipótesis de los mercados eficientes, según la cual los precios reflejan toda información disponible en cada momento del tiempo (con lo que la inversión se dirigirá siempre hacia su uso más productivo), que servirá como soporte del proceso de desregulación financiera de EE.UU. En definitiva, puesto que los mercados son eficientes bastará con que se les permita desarrollar todo su potencial creativo para situar a las economías en sus niveles de producción potencial. Desde esta perspectiva, el EB actuaría como restricción al funcionamiento eficiente del mercado en la medida en que exige niveles elevados de imposición, que alteran los incentivos del mercado, afectando así mismo a los incentivos al trabajo al ofrecer mecanismos de subsistencia alternativos al trabajo (en la forma de prestaciones por desempleo y asistencia social). Desde otra perspectiva, la producción directa de servicios, como la educación o la salud, en sistemas jerárquicos administrativos no de mercado, no sólo hurtaría a la actividad privada de nichos importantes de generación de ingresos, sino que dejaría a dichos sistemas productivos al margen de las herramientas disciplinadoras de la competencia, algo que repercutiría negativamente en la eficiencia productiva y asignativa.

En este contexto, las reformas del EB han estado informadas por 4 principios: (1) Aumentar el espacio para la producción privada de servicios de provisión pública, mediante reformas tendentes a generar cuasi-mercados en las instituciones públicas de producción de servicios públicos, y la puesta en marcha de distintas formas de cooperación público-privada como el PFI (Public Finance Investment) o más modernamente PPP (Public-Private Partnership); (2) Reformas dirigidas a reducir el impacto presupuestario de aquellos programas cuantitativamente más onerosos como las pensiones; (3) Sustitución de las medidas pasivas de protección por medidas de activación; (4) Rediseño impositivo en favor de los impuestos indirectos, teóricamente más neutrales en lo que se refiere a los incentivos y establecimiento de mecanismos de copago mediante los cuales los usuarios de determinada prestación se hacen corresponsables directos de parte de los costes ocasionados por el uso del servicio.

Estos principios rectores de reforma del EB, ni se han aplicado en todos los países de la UE, ni en los casos en los que se han aplicado se ha hecho con la misma intensidad, pero han estado presente en los procesos de reforma del EB en muchos de ellos. Para ilustrar estas líneas de actuación utilizaremos dos estrategias complementarias. En primer lugar, señalaremos algunos casos ilustrativos de aplicación de varias de estas lí- 
neas de reforma. En segundo lugar, analizaremos qué papel han tenido propuestas como las anteriores en la condicionalidad de las ayudas financieras recibidas por los países intervenidos: Irlanda, Portugal, Grecia, Chipre.

\subsection{Reforma sin complejos en el Reino Unido: hacia una sociedad de mercado}

Como es bien conocido, dentro de la UE (15) el Reino Unido representa, se podría decir que orgullosamente, el paradigma del modelo residual liberal, con un esfuerzo en protección social que sólo se sitúa por encima de los antiguos países del centro y este de Europa, Portugal y España. De hecho, el Reino Unido fue pionero durante los gobiernos conservadores de Margaret Thatcher en la puesta en marcha de una estrategia de reversión del modelo social y de empleo de la postguerra. Así y todo, como señala Grimshaw ${ }^{21}$, los elementos principales del Estados de Bienestar británico aguantaron los envites reformadores de la década de 1980, y en algunos casos fueron reforzados, al igual que lo hizo el peso del gasto en protección social sobre el PIB (que se sitúa alrededor del 25\% del PIB hasta la crisis).

El gobierno de Cameron, en lo que según The Guardian quizás sea «el conjunto de propuestas específicas más ambiciosas para reducir el estado de bienestar desde $1945 »^{22}$, ha puesto en marcha una series de medidas, recogidas en el Cuadro 1, con la intención, en sus propias palabras, de que «el trabajo no sea nunca más una mala elección financiera. Que nunca más malgastemos una oportunidad», y de acabar con un «sistema de prestaciones» que ha creado una «cultura de prestaciones» ${ }^{23}$.

${ }^{21}$ GRIMSHAW, D., «Britain's Social Model: Rapid Descent from "Liberal Collectivism" to a "Market Society"» en Vaughan-Whitehead D. (ed.), The European Social Model in Crisis: is Europe Losing Its Soul?, Edward Elgar, Cheltenham 2015, pp. $553-$ 613.

22 WINTOUR, P., «David Cameron's 17 ideas to cut extra $£ 10$ bn from welfare» en The Guardian, 25 June 2012, http://www.theguardian.com/society/2012/jun/25/david-cameronwants-further-welfare-cuts (14/04/2015)

23 Transcripción del Discurso sobre la Ley de Reforma del Bienestar, Londres, 17/02/2011 (New Stateman) 


\section{Cuadro 1}

Elementos claves de la reforma de la política social desde 2000

\begin{tabular}{|c|c|c|c|}
\hline \multicolumn{2}{|c|}{ Reformas 2000-2010 (Laboristas) } & \multicolumn{2}{|c|}{ Principales cambios post 2010 (Conservadores) } \\
\hline \multicolumn{4}{|c|}{ Protección social } \\
\hline $\begin{array}{l}\text { Prestaciones por } \\
\text { desempleo }\end{array}$ & $\begin{array}{l}\text { - aumento del con- } \\
\text { trol de disponibilidad } \\
\text { a trabajar }\end{array}$ & Intensificación & $\begin{array}{l}\text { Reducción del índice de } \\
\text { actualización, controles } \\
\text { más estrictos, sanciones } \\
\text { más duras }\end{array}$ \\
\hline $\begin{array}{l}\text { Subvenciones } \\
\text { impositivas al } \\
\text { trabajo (working } \\
\text { tax credits) }\end{array}$ & $\begin{array}{l}\text { - aumento del gasto; } \\
\text { elemento estrella de la } \\
\text { estrategia del Nuevo } \\
\text { laborismo de lucha } \\
\text { contra la pobreza }\end{array}$ & & $\begin{array}{l}\text { Congelación de los ele- } \\
\text { mentos básicos por } 3 \\
\text { años, reducción de las } \\
\text { prestaciones (aumento } \\
\text { del umbral de horas se- } \\
\text { manales), reducción del } \\
\text { índice de actualización } \\
\text { anual. }\end{array}$ \\
\hline $\begin{array}{l}\text { Prestaciones in- } \\
\text { fancia }\end{array}$ & $\begin{array}{l}\text { - aumento de las pres- } \\
\text { taciones (child tax cre- } \\
\text { dits) dirigidas a redu- } \\
\text { cir la pobreza infantil }\end{array}$ & Reversión & $\begin{array}{l}\text { Reducción de las presta- } \\
\text { ciones, eliminación del } \\
\text { algunos programas, re- } \\
\text { ducción de las desgrava- } \\
\text { ciones fiscales }\end{array}$ \\
\hline $\begin{array}{l}\text { Prestaciones a } \\
\text { familias mono- } \\
\text { parentales }\end{array}$ & $\begin{array}{l}\text { - enfoque de «pri- } \\
\text { mero trabajo» (Work } \\
\text { First) mediante el au- } \\
\text { mento del valor de las } \\
\text { prestaciones y de las } \\
\text { presiones para encon- } \\
\text { trar trabajo dificul- } \\
\text { tando el acceso al pro- } \\
\text { grama de rentas }\end{array}$ & Intensificación & $\begin{array}{l}\text { Reducción del valor real } \\
\text { de las prestaciones, au- } \\
\text { mento de las presiones } \\
\text { para encontrar trabajo } \\
\text { mediante el endureci- } \\
\text { miento d elos requisitos } \\
\text { para apoyo de rentas }\end{array}$ \\
\hline $\begin{array}{l}\text { Prestaciones por } \\
\text { dicapacidad }\end{array}$ & $\begin{array}{l}\text { - controvertido test } \\
\text { de salud para acceder } \\
\text { a prestaciones vincu- } \\
\text { ladas a los ingresos } \\
\text { (means-tested benefit) }\end{array}$ & Intensificación & $\begin{array}{l}\text { Abolición de la ayuda } \\
\text { de movilidad, endureci- } \\
\text { miento de los test de sa- } \\
\text { lud }\end{array}$ \\
\hline $\begin{array}{l}\text { Prestaciones de } \\
\text { vivienda }\end{array}$ & $\begin{array}{l}\text { - sin reformas signi- } \\
\text { ficativas }\end{array}$ & Reversión & $\begin{array}{l}\text { Reducción de las presta- } \\
\text { ciones (ver texto) }\end{array}$ \\
\hline
\end{tabular}


Protección social

\begin{tabular}{|c|c|c|c|}
\hline Pensión pública & $\begin{array}{l}\text { - sin cambios en la } \\
\text { edad de jubilación ( } 65 \\
\text { hombre, } 60 \text { mujer) } \\
\text { pero se ponen en mar- } \\
\text { cha planes para su re- } \\
\text { forma }\end{array}$ & Reversión & $\begin{array}{l}\text { Aceleración de los cam- } \\
\text { bios, a } 65 \text { (mujeres en } \\
\text { 2018), } 66 \text { (hombres y } \\
\text { mujeres en 2020), } 67 \\
\text { (2026);planes para vincu- } \\
\text { lar la edad de jubilación a } \\
\text { la esperanza de vida }\end{array}$ \\
\hline
\end{tabular}

\begin{tabular}{|c|c|c|c|}
\hline \multicolumn{4}{|c|}{ Education } \\
\hline $\begin{array}{l}\text { Educación no } \\
\text { universitaria }\end{array}$ & $\begin{array}{l}\text {-aumento significa- } \\
\text { tivo del gasto (inclu- } \\
\text { yendo gasto de inver- } \\
\text { sión) }\end{array}$ & Reversión & $\begin{array}{l}\text { Caída en el gasto real, } \\
\text { eliminación del pro- } \\
\text { grama de construcción } \\
\text { de escuelas, remoción de } \\
\text { un número creciente de } \\
\text { escuelas del control de } \\
\text { las autoridades locales }\end{array}$ \\
\hline $\begin{array}{l}\text { Educación su- } \\
\text { perior }\end{array}$ & $\begin{array}{l}\text {-introducción de ta- } \\
\text { sas a pagar por los es- } \\
\text { tudiantes, políticas } \\
\text { para aumentar la igual- } \\
\text { dad de acceso }\end{array}$ & Intensificatión & $\begin{array}{l}\text { Las tasas máximas se } \\
\text { multiplican por tres, re- } \\
\text { ducción del gasto }\end{array}$ \\
\hline \multicolumn{4}{|c|}{ Servicios de cuidados a personas } \\
\hline $\begin{array}{l}\text { Cuidados in- } \\
\text { fantiles }\end{array}$ & $\begin{array}{l}\text {-ampliación y mejora } \\
\text { de la oferta (subsidios, } \\
\text { centros SureStar -Co- } \\
\text { mienzoSeguro- en las } \\
\text { áreas de rentas bajas) }\end{array}$ & Reversión & $\begin{array}{l}\text { Reducción de la oferta } \\
\text { (se cierran muchos cen- } \\
\text { tros SureStart, reduc- } \\
\text { ción de subsidios), sin } \\
\text { política para controlar } \\
\text { el aumento de los costes } \\
\text { de guarderías }\end{array}$ \\
\hline $\begin{array}{l}\text { Cuidades per- } \\
\text { sonas mayores }\end{array}$ & $\begin{array}{l}\text { - mayor privatización } \\
\text { y financiación más res- } \\
\text { trictiva }\end{array}$ & Intensificación & $\begin{array}{l}\text { Reducción del gasto (de- } \\
\text { legación de decisiones en } \\
\text { las autoridades locales) }\end{array}$ \\
\hline \multicolumn{4}{|c|}{ Health care } \\
\hline $\begin{array}{l}\text { Servicio } \mathrm{Na}- \\
\text { cional de salud } \\
\text { (NHS) }\end{array}$ & $\begin{array}{l}\text { - aumento importante } \\
\text { del gasto, programa } \\
\text { controvertido de pri- } \\
\text { vatización de la cons- } \\
\text { trucción de hospitales } \\
\text { (PFI), escaso uso de la } \\
\text { sanidad privada }\end{array}$ & $\begin{array}{l}\text { Reversión / inten- } \\
\text { sificación }\end{array}$ & $\begin{array}{l}\text { Reducción del gasto } \\
\text { real, liberalización de la } \\
\text { producción de servicios } \\
\text { desde } 2013 \mathrm{r}\end{array}$ \\
\hline
\end{tabular}

Fuente: GRIMSHAW, D., op. cit., nota 21, pp. 565-566. 
Esa política se refleja, por ejemplo, en la actuación a la baja incluso sobre prestaciones, como las de desempleo, ya de por si las menos generosas de la OCDE, con un grado de generosidad (prestación/salario \%) en 2013, en términos netos (después de impuestos) de tan sólo el $14 \%$ para un trabajador con salario medio sin hijos (compárese con el $56 \%$ en el caso de España, por ejemplo) ${ }^{24}$. En este caso concreto se ha producido una reducción de la revalorización anual y el retraso del pago de la prestación mediante lo que se ha denominado upfront work search (búsqueda de trabajo previa) que consiste en la obligación de que los desempleados presenten un CV de forma inmediata y lo registren en el denominado Universal Jobmatch, con la finalidad de «endurecer el sistema de condiciones de los solicitantes de prestaciones» ${ }^{25}$. Esta política ha ido acompañada de una decidida apuesta a favor de la gestión privada de los servicios de empleo mediante un sistema, conocido en la literatura como «Black Box» (caja negra), por el cual el gobierno ejerce un menor control directo sobre los proveedores, con la correspondiente pérdida de gobernabilidad democrática, en favor de complejos mecanismos indirectos basados en incentivos financieros. El resultado final ha sido la creación de un mercado servicios de empleo muy concentrado, donde las cinco principales empresas contratistas (todas empresas con fines lucrativos) controlan el $51 \%$ del mercado, desplazando en muchos casos a entidades locales y organizaciones sin ánimo de lucro ${ }^{26}$. La evaluación de estos programas es compleja, entre otras muchas razones, debido a que gran parte de la motivación detrás de su puesta en marcha, como ocurre con el resto de las políticas de workfare, es incrementar la oferta efectiva de mano de obra y reducir la presión salarial. En todo caso, los estudios disponibles apuntan a la existencia de lo que en la literatura se conoce como «creaming», práctica por la cual la actividad de intermediación se concentra en aquellos desempleados más fáciles de colocar.

Otro ejemplo del tipo de actuaciones específicas realizadas en la última reforma en marcha es el cambio de la política de subsidios de vivienda. Este programa tiene un papel central en el sistema de bienestar británico al suponer un complemento importante a las prestaciones por desempleo, siendo además un elemento diferencial del propio EB del Reino Unido. Más aún, la

${ }^{24}$ OCDE, Benefits and Wages: Statistics, Net Replacement Rates - initial phase of unemployment: 2001-2013, http://www.oecd.org/els/benefits-and-wages-statistics.htm (última consulta, 22/9/2015).

25 «Chancellor George Osborne's Autumn Statement 2013», https://www .gov.uk/government/speeches/chancellor-george-osbornes-autumn-statement-2013-speech (última consulta, 22/9/2015)

${ }^{26}$ GREER, I., SCHULTE, L., y SYMON, G., «Inside the "Black Box": Ten theses on Employment Services in Britain», trabajo presentado en la Universidad de Greenwich, Junio 2014. 
dinámica de encarecimiento del coste de la vivienda, especialmente en los grandes centros urbanos, aumenta el papel que tienen las prestaciones de vivienda en el bienestar de un porcentaje creciente de población. La reforma de la política de subsidios a la vivienda incluye: utilizar el IPC para la actualización de las prestaciones de vivienda en vez del índice local de aumento de los alquileres, reducción del límite máximo del subsidio (del percentil 50 de la renta mediana al percentil 30), reducción en un $10 \%$ de la prestación por cada año en el que el beneficiario está en paro, aumento de 24 a 34 años del umbral de edad para vivienda compartida, reducción de las prestaciones para inquilinos con más habitaciones de las necesarias (el llamado «bedroom tax»), utilización de las prestaciones por vivienda para ajustar el valor máximo de prestaciones susceptible de recibir las personas potencialmente activas. Los resultados de estas medidas han sido inmediatos y se han traducido en la necesidad de poner en marcha estrategias de relocalización de personas que vivían en zonas de alquileres relativamente altos. Así mismo hay una conexión directa entre la reducción de las prestaciones por vivienda y el problema de las personas sin hogar. El propio gobierno, en una carta del Ministro de Asuntos Locales al Presidente del Gobierno, alertaba de que se estimaba en 40.000 el número de personas que podían perder el hogar y verse obligados a vivir en la calle como resultado de la reforma ${ }^{27}$.

En conjunto, el Reino Unido aparece como el caso más evidente de elección de una senda hacia un EB residual, sin ningún tipo de complejos. La reciente victoria por mayoría absoluta del partido conservador, si bien en una elección en la que el tema estrella del debate era el independentismo escocés - un independentismo que, a su vez, incorporaba la bandera del mantenimiento del $\mathrm{EB}-$ y no la política social, otorga al gobierno de Cameron cuatro valiosos años para poner en práctica su visión de la Gran Sociedad:

«La Gran Sociedad implica un enorme cambio cultural donde la gente en sus vidas diarias, en sus hogares, en sus barrios, en su trabajo no siempre acude a los funcionarios, autoridades locales o gobierno central en la búsqueda de respuesta a los problemas a los que se enfrenta, sino que en vez de ello se siente a la vez libre y capacitada para ayudarse a sí mismos y a sus propias comunidades» (D. Cameron, Liverpool, Julio 2010).

El problema, como señala Knight ${ }^{28}$, es que «está claro que Gran Sociedad, más austeridad y más recortes en los servicios públicos no nos conducen a una buena sociedad»

27 Vid. GRIMSHAW, D., op. cit, nota 21, p. 596.

28 KNIGHT, B., «From Big Society to good society Civil society should not be a substitute for the state but an addition to it» en The New Statesman, 23 November 2012. 


\subsection{La integración de política de empleo y asistencia social. El caso alemán}

Las reformas Hartz reciben su nombre de Peter Hartz, director de recursos humanos de Volkswagen y presidente de la Comisión para la Modernización de los Servicios de Empleo (Kommission für Moderne Dienstleistungen am Arbeitsmarkt). Esta Comisión, creada por el Canciller Schroeder, tenía como misión proponer líneas para la reforma del mercado de trabajo y la política de empleo, con la finalidad de combatir el alto y estancado nivel de desempleo existente en Alemania desde la reunificación, con tasas de desempleo próximas al $10 \%$ en el Oeste, y superiores al $18 \%$ en el Este, en la época en la que se activaron las reformas. El detonante de su creación fue el escándalo protagonizado por el servicio de empleo alemán (Bundesanstalt für Arbeit), al que se acuso de inflar las cifras de reempleo de los usuarios del servicios desde unos niveles reales estimados alrededor del $20 \%$, al $60 \%$ publicitado ${ }^{29}$. Las propuestas de la Comisión fueron posteriormente el núcleo de 4 reformas, conocidas como reformas Harz I a Hartz IV, que cambiaron el paisaje de la regulación laboral alemana en lo que se refiere a prestaciones por desempleo, oficinas de empleo y potenciación de un segmento del mercado de trabajo precario y empleo marginales escasamente regulado - los conocidos como «mini-jobs»- entre otros cambios. ${ }^{30}$ Las reformas se enmarcan en una visión del funcionamiento del mercado de trabajo, y de la economía en general, según la cual los problemas de desempleo están vinculados a la existencia de problemas de oferta, en concreto, a un mal diseño de los sistemas de protección social y la correspondiente alteración de los incentivos a trabajar de grupos específicos de trabajadores, frente a la opción alternativa de cobrar prestaciones sociales.

Siguiendo este diagnóstico, el principio rector de la reforma es aumentar los incentivos al trabajo mediante la combinación de (Cuadro 2): (a) reducción de la generosidad de las prestaciones de desempleo (que se integran, parcialmente, con las prestaciones sociales), (b) aumento de las sanciones por incumplimiento de la disposición a trabajar, (c) mejora de la compatibilización de ingresos y prestaciones, (d) flexibilización de la regulación de empresas unipersonales y trabajos de pocas horas (e) puesta en marcha de una renovación y reestructuración de los servicios de empleo con

29 «Here are the ideas. Now for action?» en The Economist, 27 June 2002.

${ }^{30}$ Curiosamente, en 2007 Peter Hartz fue condenado a dos años de cárcel (en suspensión de condena) y una multa de algo más de medio millón de euros por aprobar pagos ilegales para obtener el apoyo del jefe de los representantes sindicales en el Consejo de Administración de VW. 
la finalidad de transformarlos de meras oficinas de gestión de prestaciones por desempleo a oficinas de activación e intermediación ${ }^{31}$.

En lo que se refiere a las prestaciones por desempleo, antes de la reforma los desempleados con historial laboral tenían derecho a prestaciones por desempleo durante un periodo de 6 a 32 meses (dependiendo de la edad y la duración del empleo anterior) por una cuantía equivalente al 67\% (60\% en el caso de no tener hijos) de su último ingreso neto, con un máximo de $4250 € /$ mes. Al agotarse la prestación, la asistencia por desempleo reducía este porcentaje al $57 \%$, sin límite temporal, algo inusual en los países de la OCDE. Tras la reforma, los desempleados tienen derecho a prestación por desempleo en función de su capacidad para trabajar. La prestación tipo I, dirigida a las personas con empleo anterior dura de 6 a 12 meses, pasando posteriormente a recibir la prestación tipo II, que es de tipo fijo y exige comprobación de ingresos (means tested), no está vinculada a los ingresos recibidos en el empleo anterior y es menos generosa que la asistencia social.

\section{Cuadro 2}

Cronología y medidas principales de las reformas Hartz

Ley y fecha de entrada en vigor

Medidas principales

Hartz I : Primera ley para la moderniza- Puesta en marcha de Agencias de Servicios ción de los servicios del mercado de tra- de Empleo bajo (2003)

Hartz II : Segunda ley para la moderniza- Introducción de las compañías unipersonación del mercado de trabajo (2003) les; Reforma de los empleos de bajos ingresos («mini»y «midi jobs»)

Hartz III : Tercera ley para la moderniza- Reestructuración de la Oficina Federal de ción de los servicios del mercado de tra- Trabajo

bajo (2004)

Hartz IV : Cuarta ley para la moderniza- Las prestaciones de asistencia por desemción de los servicios del mercado de tra- pleo y la asistencia social se combinan bajo (2005) para formar la prestación por desempleo II: nueva definición de lo que es un «empleo aceptable», sanciones, aumento en las tasas de compatibilidad de prestaciones e ingresos laborales, servicios a la comunidad

Ley para la reforma del mercado de tra- Reducción de la duración de la prestación bajo (2006) por desempleo

Fuente: Ochel op. cit., p. 18

31 OCHEL, W., «Hartz IV - Welfare to Work in Germany» en CESifo DICE, Report 2/2005, 2005, pp. 18-25. 
Junto con los cambios en el sistema de prestaciones por desempleo y en los servicios de empleo (cuya gestión se abre parcialmente al sector privado mediante un sistema de subcontratación, basado en la caracterización de los demandantes de empleo en cuatro tipos en función de su empleabilidad y su asignación en itinerarios distintos), uno de los elementos más destacados de la reforma es la creación de un tipo de empleos, denominados «minijobs» $\mathrm{y}$ «midijobs», abiertos a todos los trabajadores, no solamente a los desempleados, y definidos como empleos con unos ingresos por debajo de los 450 $€ /$ mes (850 €/mes en el caso de los midijobs). Los minijobs están exentos de cotizaciones a la seguridad social por parte de los trabajadores que así lo soliciten, mientras que los midijobs pagan contribuciones crecientes desde los 450 a los $850 €$. En definitiva, estamos hablando de empleos con contribuciones sociales reducidas ${ }^{32}$. Junto a ello se habilitan subsidios para la creación de empresas unipersonales $I c h-A G$ («Mi Inc») por un máximo de tres años por cantidades decrecientes $(600-360-240 € /$ mes $)$ para rentas inferiores a $20000 € /$ año. Igualmente se liberalizan los contratos temporales, eliminándose determinadas restricciones y ampliando la exención de indemnización por despido para este tipo de contrato para empresas de hasta 10 trabajadores (antes 5).

Otra de las características destacables de las reformas Hartz es la obligación de realizar una evaluación completa de los resultados de la misma, algo sin duda digno de alabanza comparado con lo que ocurre en países como España donde la evaluación de las políticas públicas, tanto ex-ante como ex-post, no es nada frecuente. Los resultados de estas evaluaciones son favorables en lo que se refiere a la reforma de los servicios de empleo y los subsidios ${ }^{33}$. Sin embargo, la estrategia de resolver los problemas de pobreza, preferentemente, mediante políticas de empleo entra en conflicto con la heterogeneidad de la pobreza, al tiempo que, frecuentemente, las situaciones de desempleo de larga duración se ven sustituidas por situaciones de empleo de bajos salarios ${ }^{34}$.

Como se puede apreciar en el Gráfico 4, la aplicación de estas reformas ha generado también un aumento significativo del peso del empleo atípico (empleo marginal-minijobs, empleo temporal y empleo a tiempo par-

${ }^{32}$ Los empleadores pagan una contribución social del 30\%. Los detalles de la normativa aplicable desde 2013 se pueden encontrar en Ministerio Federal de Empleo y Asuntos Sociales: «450 Euro mini jobs/marginal employment». Disponible en http://www.bmas.de/EN/OurTopics/Social-Security/450-euro-mini-jobs-marginal-employment.html

33 JACOBI, L. y JOCHEN, K., «Before and after the Hartz Reforms: The Performance of Active Labour Market Policy in Germany» en IZA, DP No. 2100, Bonn, 2006.

${ }^{34}$ PROMBERGER, M., «Nine years of Hartz IV - a welfare reform under scrutiny» en Cuadernos de Relaciones Laborales, 33 n. ${ }^{\circ} 1,2015$, pp 35-63. 
cial), hasta alcanzar el 21,4\% del empleo total (24\% del empleo asalariado). Como se puede observar, el aumento del empleo atípico y de bajos salarios precede a las reformas Hartz y está vinculado, entre otros factores, a la apertura de muchos mercados de servicios públicos a proveedores privados que compiten vía bajos salarios con las empresas públicas del sector ${ }^{35}$. Sin embargo, las reformas Hartz tuvieron un papel importante en la potenciación de esta dinámica y a la hora de impedir que la recuperación de 2005, llegara también a este segmento del mercado. En lo que se refiere al empleo, aunque las reformas parecen haber incrementado el flujo de trabajadores del desempleo al empleo, al hacer más fácil el empleo temporal también han incrementado el flujo desde éste al desempleo, neutralizándose, por lo tanto, su efecto global sobre los niveles de empleo (Bosch, 2013). Junto con otros acontecimientos, el crecimiento de este segmento atípico de mercado de trabajo explica el aumento de la desigualdad de ingresos que, en términos de mercado ha aumentado a lo largo de la última década de $149,1 \%$ en 2005, al 56,4\% en 2013, (del 26,1\% al 29,7\% en términos de ingresos disponible, SILC).

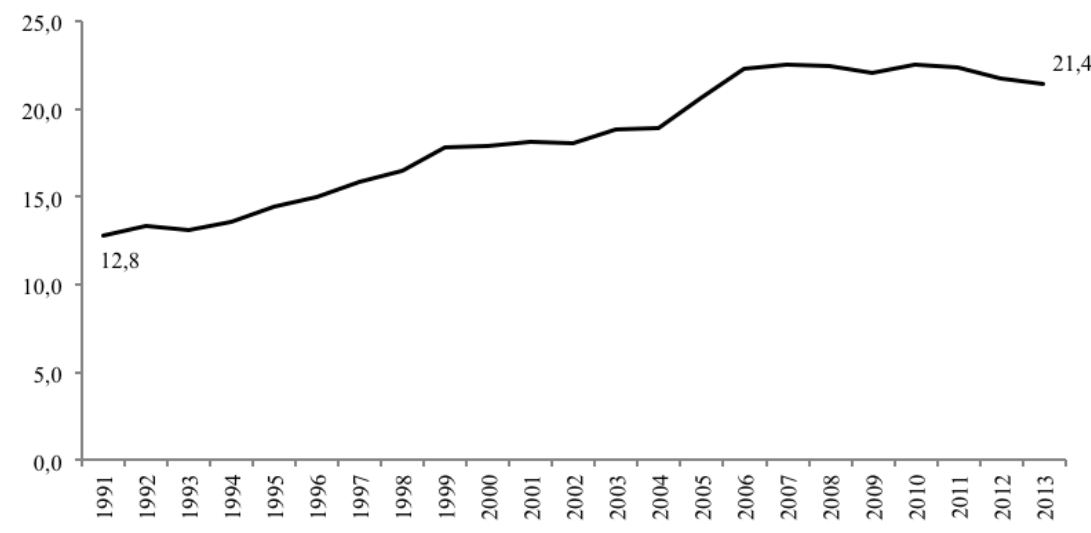

Gráfico 4

Evolución de empleo atípico en Alemania.

Fuente: Statistisches Bundesamt, Microcensus y elaboración propia.

35 BOSCH, G., «Low Wages in Germany and the Europe an Imbalance Problem» en PALLEY T. y HORN G., Restoring Shared Prosperity: A Policy Agenda from Leading Keynesian Economists, 2013, pp. 183-190. CreateSpace Independent Publishing Platform. 


\section{3. «Here, there and everywhere»: la reforma generalizada de los} sistemas de pensiones

Las pensiones son el núcleo central de los EB modernos, al menos, en lo que se refiere a población cubierta en el presente (pensionistas) y en el futuro (trabajadores actuales). Igualmente es el ámbito principal de gasto, con valores que en la UE van del 7,3\% del PIB en Irlanda, al 17,5\% en Grecia, con un valor medio en la UE (15) del 13,5\% y $12 \%$ en España. Por último, los sistemas de pensiones existentes en Europa parecen haber resuelto de forma satisfactoria el mantenimiento de rentas en la tercera edad, por lo menos en lo que se refiere a las tasas de pobreza: como se puede apreciar en el Gráfico 5, en la mayoría de países de la UE las tasas de pobreza de los mayores de 65 años son inferiores (o similares) a las tasas de pobreza del conjunto de la población.

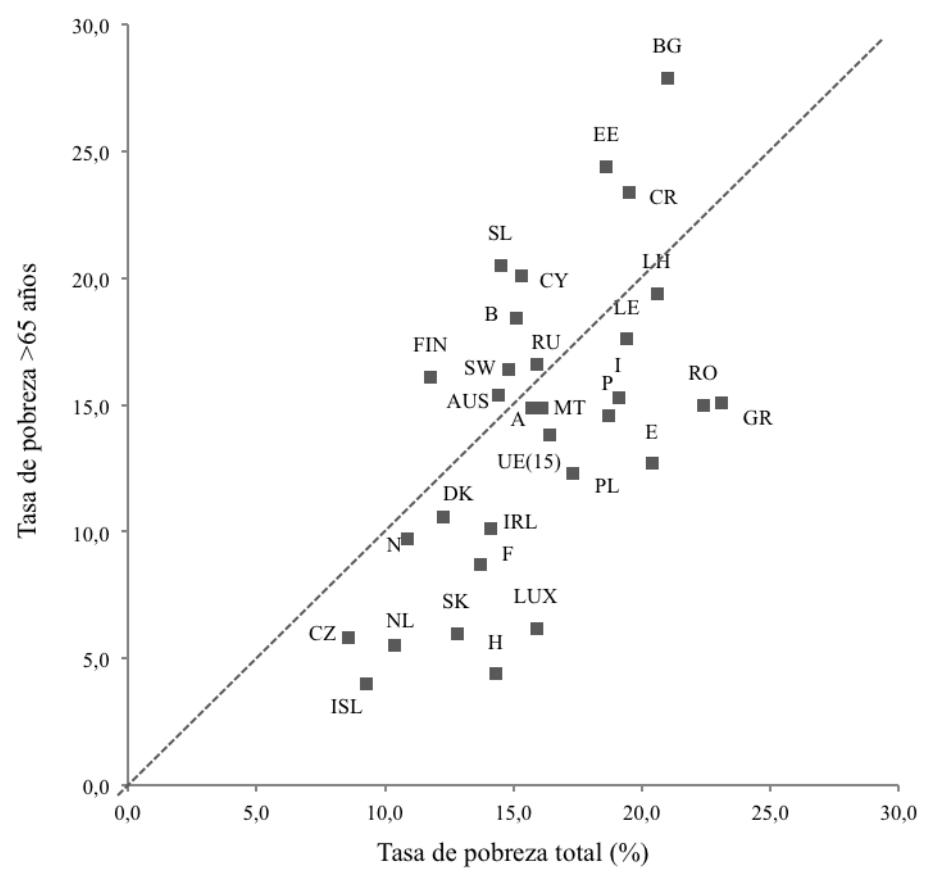

\section{Gráfico 5}

Tasa de riesgo pobreza total y para mayores de 65 años en Europa. 2013

* Definida como población con ingresos por debajo del $60 \%$ de la renta mediana de cada país.

Fuente: SILC, Eurostat y elaboración propia 
Esta política razonablemente exitosa se ha visto sometida a fuertes presiones de reforma, al menos desde que en 1994 el BM (Banco Mundial) publicara su famoso informe Averting crisis in old age ${ }^{36}$, donde alertaba sobre las consecuencias que tendría para los sistemas de pensiones basados en el reparto (también conocidos como Pay As You Go) el aumento de la denominada Tasa de Dependencia (definida como el cociente entre la población de más de sesenta y cuatro años y la población potencialmente activa), derivado del aumento de la esperanza de vida y la caída de la tasa de natalidad. Independientemente de la debilidad teórica y empírica de muchos de los análisis del efecto de dicha dinámica sobre los sistemas de pensiones públicos, tema que lamentablemente no podemos tratar en estas páginas por cuestión de espacio ${ }^{37}$, lo cierto es que durante las últimas décadas muchos países europeos han procedido a ajustar, de forma más o menos radical, los programas de pensiones con la finalidad de reducir el impacto presupuestario que en ausencia de reformas tendría el aumento de la Tasa de Dependencia. En la mayor parte de países los cambios han sido de una naturaleza paramétrica, esto es, se ha mantenido la lógica del sistema de protección, actuando sobre los parámetros que determinan la cuantía de la pensión y los requisitos para recibirla. Estos cambios han tomado la forma de: (1) retraso de la edad de jubilación, pasando de los sesenta y cinco a los sesenta y siete años, (2) alargamiento del período de cómputo, de forma que la pensión se vincula a los ingresos obtenidos durante un mayor número de años, (3) incorporación de ajustes por el aumento de la esperanza de vida, (4) reducción de las opciones de jubilación anticipada, y (5) potenciación de los sistemas de pensiones privados complementarios.

Todos estos cambios tienen en común el ejercer un efecto a la baja sobre el gasto en pensiones en términos de PIB, como si hubiera una cifra mágica de gasto en este ámbito que no se pudiera superar, lo cual en un contexto de población creciente de pensionistas significa la reducción de la participación de los futuros jubilados del PIB futuro. Con ello se traslada la responsabilidad del mantenimiento de rentas en la tercera edad, al menos parcialmente, del Estado a las personas. Si antes «bastaba» con trabajar y cotizar para tener garantizada una pensión razonable (en términos de cobertura con respecto a los ingresos laborales del pasado), ahora, de forma creciente, se extiende la idea de que ello no va a ser suficiente, desplazando la responsabilidad al trabajador y futuro pensionista mediante la contratación

36 WORLD BANK, Averting the old age crisis: policies to protect the old and promote growth, Oxford University Press, Washington D.C., 1994.

37 Sobre este tema véase, por ejemplo, ESTEVE, F. y MUÑOZ DE BUSTILLO, R., «Mitos y falacias populares en el debate acerca de los sistemas de pensiones», Estudios de Economía Aplicada, 22, n. ${ }^{\circ}$ 2, 2004, pp. 289-316. 
de algún plan de ahorro/pensiones ocupacional o privado complementario. Este cambio tiene efectos importantes por tres razones. En primer lugar, porque frente a los sistemas de pensiones públicos, que habitualmente aseguraban una pensión determinada siempre que se cumplieran unos requisitos, esto es, eran sistemas de pensión fija y con garantía de actualización anual (a precios o salarios), los planes ocupacionales o privados no garantizan ni lo uno ni lo otro. En segundo lugar, porque los trabajadores tienen distinta capacidad de ahorro en función de su salario y circunstancias personales, lo que a su vez afecta a su capacidad de acumulación de riqueza en forma de un fondo de pensión, con el consiguiente riesgo de aumento de las desigualdades en la tercera edad. En palabras de Richard Titmuss, esta opción supondría el riesgo de aparición de «dos naciones en la tercera edad; más desigualdades en el nivel de vida tras la jubilación que durante la vida activa ${ }^{38}$. En tercer lugar, porque el deterioro de las pensiones públicas y el respaldo de una política de pensiones privadas puede afectar al apoyo mayoritario de la población a esta política pública y debilitar en el futuro el respaldo a este tipo de programas, facilitando su residualización ${ }^{39}$.

\subsection{La reforma global. El caso de los países sujetos a intervención financiera como resultado de la crisis económica de 2008}

Los países intervenidos y bajo ayuda financiera de la UE como resultado de las dificultades de acceso a financiación internacional asociadas a la crisis económica y financiera, son un ejemplo paradigmático de las incoherencias existentes entre la defensa formal del MSE (Modelo Social Europeo) por parte de las instituciones comunitarias, y su exigencia de debilitamiento como contrapartida al acceso a ayuda financiera comunitaria. Los distintos Memorandos de Entendimiento (MoU, Memorandum of understanding en la terminología comunitaria) firmados, in extremis, por los países intervenidos (Irlanda, Grecia, Chipre y Portugal) y la denominada «Troika» (Eurogrupo, FMI y BCE), son un magnífico ejemplo de esa visión bipolar de las autoridades comunitarias a la que nos hemos referido más arriba. Subyacente a los MoU está una visión de los problemas económicos de los países intervenidos que hace caso omiso de las circunstancias y problemas específicos de los mismos, y que se puede resumir en la necesidad de aplicar «reformas estructurales» idénticas, entendidas como reduc-

38 TITMUSS, R., M. Essays on «The Welfare State», Allen and Unwin, London, 1958, p. 74

39 Para una panorámica de las reformas de los sistemas de pensiones en una muestra de países europeos tras la crisis véase, NATALI, D. y STAMATI, F., Reforming pensions in Europe: a comparative country analysis, Working Paper 2013/08, ETUI, Bruselas 2013. 
ción del gasto público - que ha de tener prioridad sobre el aumento de los ingresos - , especialmente, gasto social, desregulación del mercado laboral, junto con algunas medidas puntuales de liberalización de mercados y privatización de empresas públicas. Con el paso del tiempo los MoU se han ido complejizando en lo que se refiere a los detalles, dejando muy poco margen a la soberanía nacional para aplicar las medidas que considere más oportuna para alcanzar los equilibrios macroeconómicos (fundamentalmente presupuestarios) comprometidos. El Cuadro 3, que reproduce los elementos principales de los MoU de los países intervenidos, refleja perfectamente la identidad de la receta aplicada, a pesar de las numerosas evidencias disponibles de los efectos contractivos derivados de la política de ajuste aplicada ${ }^{40}$, y su incidencia sobre programas centrales del EB como la salud o las pensiones. Las exigencias de alcanzar y mantener superávit primarios durante el medio largo plazo hacen más difícil que tras la superación de la crisis se pueda volver a niveles similares de protección social, con lo que no sería extraño que en el futuro estos países se vean obligados a situarse en el extremo bajo de intensidad de EB por «necesidades del guión».

\section{Cuadro3}

Tipos de medidas de ajuste fiscal y reformas estructurales de los países intervenidos.

\begin{tabular}{|c|c|c|}
\hline País y fecha & Cantidad & Medidas de reforma estructural y ajuste fiscal* \\
\hline $\begin{array}{l}\text { Irlanda } \\
12 / 2010 \\
\text { En situación de «se- } \\
\text { guimiento post-pro- } \\
\text { grama» desde } 2013\end{array}$ & 85.000 mill. $€$ & $\begin{array}{l}\text { - Ajuste fiscal de } 3,8 \% \text { PIB en } 2011 \text { ( } 55 \% \text { caída del gasto, } \\
1 / 3 \text { del cual es gasto social). Superávit primario en } 2015= \\
3.2 \% \\
\text { - Reducción del salario mínimo en } 12 \% \text {. } \\
\text { - Revisión de la extensión de convenios colectivos } \\
\text { - Cambios en la prestación por desempleo. } \\
\text { - Potenciación de las privatizaciones }\end{array}$ \\
\hline $\begin{array}{l}\text { Grecia } \\
05 / 2010\end{array}$ & $\begin{array}{l}77.300+ \\
30.000 \\
\text { mill. } €\end{array}$ & $\begin{array}{l}\text { Ajuste fiscal basado en la reducción del gasto ( } 7 \% \text { del PIB) + } \\
4 \% \text { de ingresos excluyendo impuestos directos. } \\
\text { - Lucha contra el fraude fiscal } \\
\text { - Sustitución de las pagas extraordinarias de empleados pú- } \\
\text { blicos por un bono fijo de } 1000 € \text { ( } 800 € \text { para pensionistas). } \\
\text { - Reducción en } 8 \% \text { de las pensiones superiores a } 1400 € \\
\text { - Aumento de la edad de jubilación a } 65 \text { años } \\
\text { - Reforma del mercado de trabajo } \\
\text { - Reducción del empleo público }\end{array}$ \\
\hline
\end{tabular}

40 Vid. MUÑOZ DE BUSTILLO, op. cit., nota 2. 


\begin{tabular}{|c|c|c|}
\hline País y fecha & Cantidad & Medidas de reforma estructural y ajuste fiscal* \\
\hline $\begin{array}{l}\text { Portugal } \\
05 / 2011 \\
\text { En situación de «se- } \\
\text { guimiento post-pro- } \\
\text { grama» desde } 2014\end{array}$ & $\begin{array}{l}26.000 \text { mill. } € \\
\text { (utilizado el } \\
93 \% \text { ) }\end{array}$ & $\begin{array}{l}\text { - Ajuste fiscal concentrado en el gasto del 5,5\% en } 2011 . \\
\text { Superávit primario del 2,9\% desde } 2015 \\
\text { - Reducción de salarios públicos en } 2011 \text { del } 5 \% \\
\text { - Contribución especial de los pensionistas } \\
\text { - Reducción del empleo público ( } 1 \% \text { por año en Admon. } \\
\text { Central, } 2 \% \text { en local) } \\
\text { - Reducción de prestaciones no contributivas } \\
\text { - Concentración escolar } \\
\text { - Aumento de los impuestos indirectos } \\
\text { - Acelerar el programa de privatizaciones (Aeroportos de } \\
\text { Portugal, TAP, GALP, EDP, REN, Correios de Portugal. } \\
\text { - Aumento del copago en sanidad } \\
\text { - Reforma de la legislación laboral: reducción de la indem- } \\
\text { nización por despido, revisión de las prestaciones por de- } \\
\text { sempleo (duración máx. } 18 \text { meses, prestación máx. } 25 \text { veces } \\
\text { el índice de apoyo social (pero reducción del periodo mí- } \\
\text { nimo de empleo de } 15 \text { a } 12 \text { meses). } \\
\text { - Control de aumentos del Salario mínimo. } \\
\text { - Limitar la extensión de los acuerdos colectivos } \\
\text { - Reducción de las cotizaciones sociales }\end{array}$ \\
\hline
\end{tabular}

- Ajuste fiscal: reducción de: gasto farmacéutico, primas horas extraordinarias para doctores en hospitales, compras militares, gastos en elecciones, subsidios a residentes en zo-

Grecia

$03 / 2012$

\section{Chipre}

02/2013
165.500 mill. $€$ - Objetivo superávit primario de 4,5\% en 2013

- Acelerar el ritmo de privatizaciones

- Reducción del empelo público

- Reducción del salario mínimo 22\% (32\% menores de 25)

- Revisión del sistema de Negociación Colectiva

- Ajuste fiscal: superávit primario para 2016 y 4\% en 2018. Ajuste de 6,5\% GDP en 2013-14.

- Reducción de los salarios públicos: $1,2 \%$ del PIB en 2013; 3\% de los salarios en 2014; nueva contribución de $1,5 \%$ para acceder a la salud pública..

- Reducción del gasto social y aumento de las exigencias de los programas sujetos a comprobación de ingresos

- Reforma de las pensiones: asociar la edad de jubilación a la esperanza de vida; penalización por jubilación anticipada; cálculo de la pensión considerando toda la vida laboral

- Reforma del sistema de salud: aumento de copago

- Aumento de los tipos del IVA

- Programa de privatizaciones

- Eliminación del ajuste de coste de vida de los salarios de los empelados públicos.

- Visto bueno de la troika de posibles aumentos del salario mínimo.

- Liberalización del sector servicios 


\begin{tabular}{|c|c|c|}
\hline País y fecha & Cantidad & Medidas de reforma estructural y ajuste fiscal* \\
\hline $\begin{array}{l}\text { Grecia } \\
07 / 2015\end{array}$ & $\begin{array}{l}50-86.000 \text { mill. } \\
€ \text { (sin cerrar) }\end{array}$ & $\begin{array}{l}\text { - Reforma de las pensiones para compensar el fallo del Tri- } \\
\text { bunal Constitucional sobre la reforma de } 2012 \text {. } \\
\text { - Reformas de mercados incluyendo: libertad de horarios } \\
\text { comerciales, farmacias y apertura de mercados profesiona- } \\
\text { les regulados } \\
\text { - Privatización de la red de trasmisión de electricidad AD- } \\
\text { MIE (o soluciones similares) } \\
\text { - Revisión del sistema de negociación colectiva, despidos } \\
\text { colectivos. } \\
\text { - Creación de un fondo independiente con los activos de } \\
\text { empresas públicas (50000 millones), bajo supervisión euro- } \\
\text { pea, para su venta. Los ingresos distribuirán: } 50 \% \text { recapitali- } \\
\text { zación de bancos, } 25 \% \text { para la amortización de deuda y } 25 \% \\
\text { para inversiones. } \\
\text { - Reforma y despolitización de la AAPP griega y su coste. } \\
\text { - El gobierno consultará con las Instituciones acreedoras } \\
\text { toda la nueva legislación antes de trasladarla al Parlamento. } \\
\text { - Revisión de toda la legislación (excepto la referida a la } \\
\text { crisis humanitaria) aprobada desde el cambio de gobierno } \\
\text { (20/02/2015) }\end{array}$ \\
\hline
\end{tabular}

* No se incluye el sector financiero.

Fuente: elaboración propia a partir de European Economy, The Economic Adjustment Programme for Cyprus, Occasional Papers 149, Bruselas. 2013, European Economy, The Economic Adjustment Programme for Ireland, Occasional Papers 76, Bruselas. European Economy, The Economic Adjustment for Portugal, Occasional Papers 79, Bruselas., EUROPEAN ECONOMY, The Economic Adjustment Programme for Greece, Occasional Papers 61, Bruselas., EUROPEAN ECONOMY (2012), Eurosummit Statement Brussels, 12 July 2015. SN 4070/15.

\section{Conclusiones}

De acuerdo con la narrativa que precede a esta sección, el EB habría sido capaz de mantener a lo largo del tiempo su cuota parte de recursos en términos agregados, al tiempo que sus programas todavía seguirían siendo, a mediados del segundo decenio del siglo XXI, elementos centrales y cotidianos del bienestar de los ciudadanos europeos. Pero ello no debe ser visto con complacencia ni debe ser interpretado en términos de ausencia de cambios. Tan importante como el mantenimiento de las grandes magnitudes de gasto social es la existencia de multitud de cambios, a distintos niveles y con distinta intensidad, que poco a poco van alterando el paisaje de la protección social en muchos países europeos. Detrás de dichos cambios están dos elementos transversales. 
El primero de ellos es la devolución a los propios ciudadanos de gran parte de la responsabilidad del bienestar de los ciudadanos asumida en el pasado por las instituciones del EB. El futuro es incierto y no se puede conocer, pero las líneas actuales señalan hacia un futuro en donde parcelas cada vez más numerosas del bienestar, cuya responsabilidad de cobertura quedaba en manos de la colectividad entendida como el Estado en cualesquiera de sus formas, pasen a estar de forma creciente en manos de los particulares y de su capacidad de hacerse oír, mediante su poder adquisitivo, en nuevos mercados privados desarrollados en lo que antes eran los márgenes de la provisión pública. Detrás de esta deriva hay dos elementos diferenciales pero complementarios. El primero de ellos, tan antiguo como la propia política social ${ }^{41}$, es la tesis de los efectos no deseados, el impacto negativo que las actuaciones bienintencionadas pueden tener sobre los comportamientos humanos con resultados finales contrarios a los buscados. Las políticas estructurales de reforma del mercado de trabajo y la protección social dirigidas a reequilibrar los incentivos al trabajo serían un ejemplo de ello. El segundo, tiene que ver con una dinámica según la cual el retroceso del sector público en ámbitos importantes de la producción y provisión de servicios deja espacio libre para la entrada de actores del sector privado, abre nuevos espacios de producción y acumulación que antes le estaban vetados a las empresas privadas.

El segundo elemento transversal lo constituye las crecientes restricciones financieras y regulatorias a las que se enfrentan los EB en un mundo cada vez más globalizado y, específicamente, en la UE, con un sistema monetario único en el que los países han perdido gran parte de su capacidad de ejercicio de una política económica y regulatoria autónoma. Esta limitación se ha mostrado con todo su dramatismo en el detalle con el que las autoridades europeas diseñaban el debilitamiento de los EB de los países intervenidos tras la crisis económica y financiera. Estas restricciones, obviamente, no son absolutas, pero la negativa de la UE a desarrollar un espacio social europeo integrado y libre de las tensiones propias de la competencia y el dumping social, hace que cada vez sea más difícil mantener políticas sociales propias y sistemas fiscales suficientes al margen de lo que hagan en los países competidores.

Este nuevo contexto para los viejos Estados de Bienestar ha hecho que se replantee tanto su vigencia como su sostenibilidad. Ambas cuestiones han sido tratadas desde hace algo más de una década por parte de una nueva corriente de estudios del EB que han planteado la necesidad de pro-

${ }^{41}$ HIRSCHMAN, A.O., Retóricas de la intransigencia, Fondo de Cultura Económica, México D.F., 1991. 
ceder a la transformación del mismo en una institución centrada en políticas que «preparen en vez de reparen», en una frase que se ha convertido en el lema de dicha perspectiva. Se habla así de «Estado de Bienestar centrado en la inversión social», de «Estado de Bienestar desarrollista» o de «liberalismo inclusivo ${ }^{42}$. La idea es reforzar las actuaciones del EB con efecto positivo sobre la acumulación de capital humano y su activación, lo que exige priorizar la educación en todos los niveles incluyendo la educación 0-3, la salud, el respaldo a las tareas de reproducción social-familiar para facilitar la plena activación de las personas, especialmente, las mujeres, etc. En definitiva, la potenciación de lo que Myrdal denominaba «política social productiva $\gg^{43}$.

El análisis cuantitativo de Dräbing ${ }^{44}$ sobre la evolución y distribución del gasto público entre lo que denomina gasto compensador (el «tradicional» del EB) y gasto capacitador (el que se vincularía con la inversión social en los términos señalados más arriba), concluye que durante el periodo 1998-2010, hay cierta tendencia entre los países europeos al aumento del peso del gasto capacitador, aunque existe una clara brecha en lo que se refiere a la importancia relativa otorgada a ambos tipos de gasto entre los países meridionales y orientales de Europa y los países nórdicos. Este resultado pone de manifiesto, ya para acabar, uno de los problemas a los que se enfrenta esta visión dicotómica de los gastos sociales, y por ende, el propio concepto de EB de inversión social, el hecho de que muy probablemente los gastos compensadores y capacitadores, en gran parte, no son gastos sustitutivos sino complementarios, esto es, la inversión social no sustituye la inversión compensatoria (o lo hace tan solo en parte), aunque sirva para sentar las base de una economía más productiva que facilite la cobertura de las necesidades sociales de la población tradicionalmente objeto de las actuaciones del EB.

En la medida en que la inversión social sirva para potenciar el crecimiento económico, el EB de inversión social sentará también las bases para el mantenimiento del EB tradicional. Sin duda alguna el requisito para el mantenimiento del EB es una economía productiva que genere suficiente

${ }^{42}$ MOREL, N., PALIER, B. y PALME, J. (eds), Towards a Social Investment Welfare State?: Ideas, Policies and Challenges, Polity Press, London 2012.

43 ANDERSON, J., «Investment or Cost? The Role of the Metaphor of Productive Social Policies in Welfare State Formation in Europe and the US 1850-2000», comunicación presentada en el World Congress in Historical Sciences, Sydney, Julio 2005.

44 DRABING, V., «The role of the State: Reform pressures and welfare Reform Towards Social Investment» en BLEVARÝ, M. y VESEKOVÁ, M. (eds.), Let's go work. The future of labour in Europe, Bruselas, Centre for European Policy Studies, CEPS, 2014, pp. 159-182, http://www.academia.edu/7794772/Let_s_Get_to_Work_The_Future_of_Labour_in_Europe $(14 / 10 / 2015)$ 
excedente como para financiar los programas de gasto e inversión social. Pero ello, siendo necesario, no es suficiente. Si algo hemos aprendido tras décadas de estudios sobre la «crisis del EB» es que hay múltiples variedades de capitalismo y posibles combinaciones de Estado y mercado, público y privado, compatibles con una economía de mercado que funcione. El mantenimiento del EB exige también contar con la correlación de fuerzas y el apoyo social y político necesario para respaldar sus políticas y la correspondiente redistribución de las rentas generadas en el mercado. Será lo que ocurra en estos dos ámbitos lo que determine el futuro de los Estados de Bienestar europeos. 


\section{Derechos de autor (Copyright)}

Los derechos de autor de esta publicación pertenecen a la editorial Universidad de Deusto. El acceso al contenido digital de cualquier número de Cuadernos Europeos de Deusto (CED) es gratuito, transcurridos 6 meses desde su publicación. Los trabajos podrán descargarse, copiar y difundir, sin fines comerciales y según lo previsto por la ley. Así mismo, los trabajos editados en CED pueden ser publicados con posterioridad en otros medios o revistas, siempre que el autor indique con claridad y en la primera nota a pie de página que el trabajo se publicó por primera vez en CED, con indicación del número, año, páginas y DOI (si procede). 